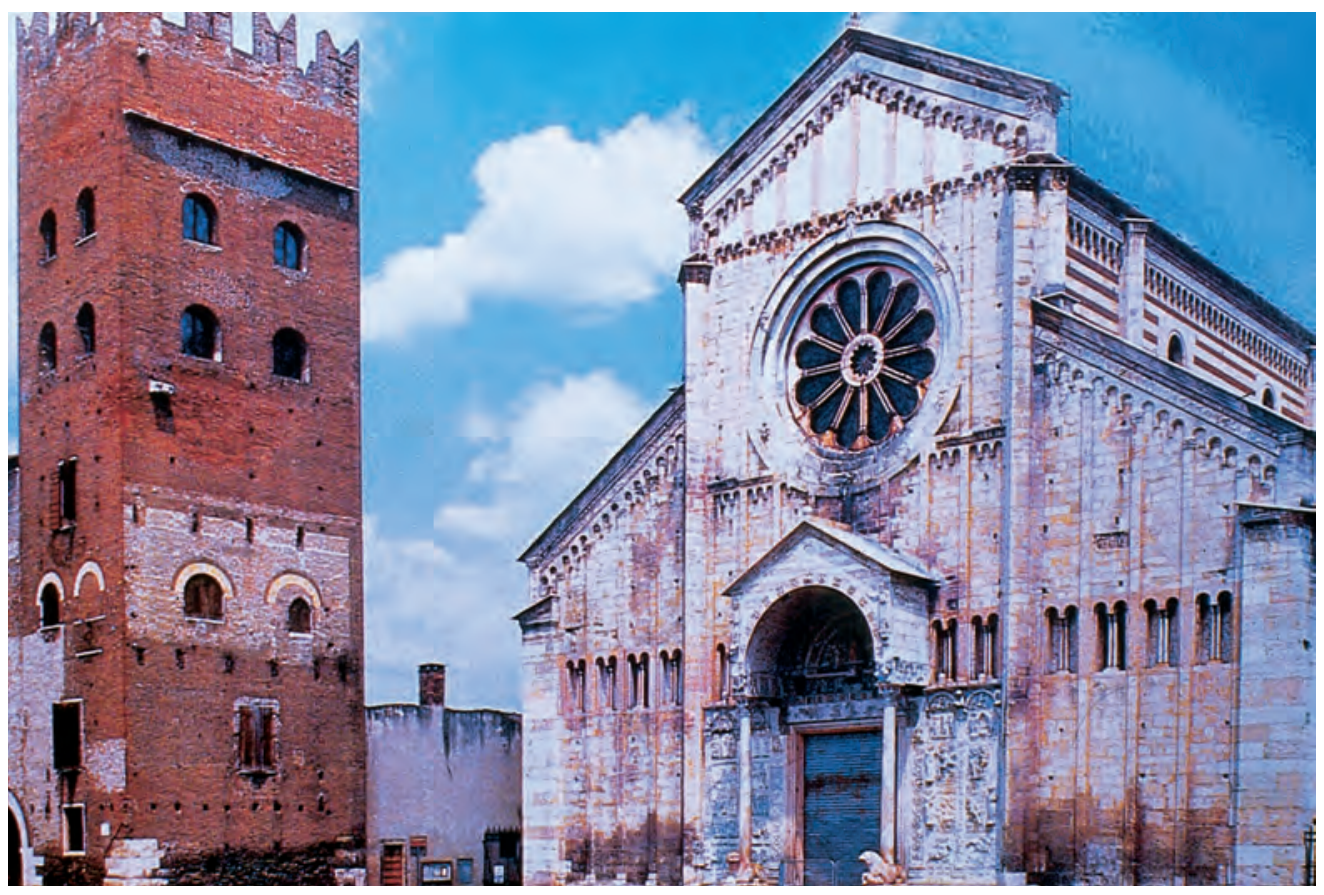

1. Vista de la iglesia de San Zeno, la torre y el palacio abacial

\title{
Recomposición de un espacio arquitectónico para la recuperación de un gran fresco medieval La abadía de San Zeno en Verona
}

Libero Cecchini *

La puesta en valor de un gran fresco medieval ubicado en la Abadía de San Zeno forma parte de las intervenciones acometidas en este conjunto en las últimas dos décadas, que se han explicado en parte en el artículo anterior. Las cuestiones surgidas durante la operación han requerido la aplicación de una metodología rigurosa de investigación y restauración donde la colaboración interdisciplinar entre arqueólogos, arquitectos, ingenieros, geólogos, químicos y restauradores ha resultado fundamental para llevar a buen puerto la recuperación de una pintura de gran valor histórico y artístico.
Reconstruction of an architectonic space for the recuperation of a large medieval fresco in San Zeno Abbey in Verona. The restoration of a large medieval fresco situated inside San Zeno Abbey formed part of the interventions performed on this monument in the last two decades, partly described in the previous article. Issues that arose during the works advised the putting into practice of a rigorous research and restoration process, in which the interdisciplinary collaboration of archaeologists, architects, engineers, geologists, chemists and restorers played a crucial part in the recuperation of a painting of great historic and artistic value. 
El presente trabajo contempla la nueva conformación de un espacio con el objetivo de recuperar el fresco "Homenaje de los pueblos de la tierra a Federico II", ubicado en la pared septentrional externa de la torre de la Abadía de San Zeno Maggiore en Verona (fig. 1). Este fresco constituye, sin duda, uno de los testigos más importantes y significativos de la pintura del siglo XIII en el Norte de Italia, tanto por su calidad figurativa como por la singularidad del tema (fig. 2).

La gran escena pintada se divide en tres franjas: en la parte superior se encuentra un magnífico friso con volutas dobles anudadas a máscaras monstruosas; en la zona intermedia, la escena principal con un largo cortejo de figuras que avanza desde una ciudad salpicada de torres para rendir homenaje a Federico II, sentado sobre el trono; en la franja inferior se recoge una elaborada escena de la caza del jabalí.

Desgraciadamente, la lectura de esta gran pared (50 $\mathrm{m}^{2}$ aproximadamente) ha estado desde siempre condicionada, no sólo por la dificultad de acceso a la pared misma sino, sobre todo, por la presencia de un forjado que la dividía por la mitad escondiendo partes relevantes de la superficie pintada.

La existencia de la torre está documentada desde el año 1169 y presenta claramente dos fases constructivas: la primera, del siglo XII, que comprende los dos forjados originarios; la segunda de finales del siglo XIII y principios del siglo XIV, que se corresponde con el recrecido que alcanza el nivel actual (fig. 3). Esta parte superior de la torre, más reciente, se distingue del sector inferior por el menor espesor de los muros, por el tipo de ladrillo empleado -más claro- y por la construcción de las ventanas, cuyos arcos no son de toba, sino de ladrillo.

La torre nació exenta, pero poco después se le adosó por el lado Norte un edificio constituido por dos grandes espacios: la logia, en la primera planta, y una estancia superior. En esta gran logia, abierta hacia el interior del monasterio, se pintó el gran fresco del cortejo. Posteriormente, estando de abad del cenobio Giuseppe della Scala, esta estructura porticada fue transformada en un edificio mucho más grande que el conservado actualmente, como se puede observar a tenor de las trazas de los sillares de piedra presentes en la pared Oeste del Callejón de la Abadía y de los restos del techo todavía presentes en la pared Norte de la Torre (fig. 4).

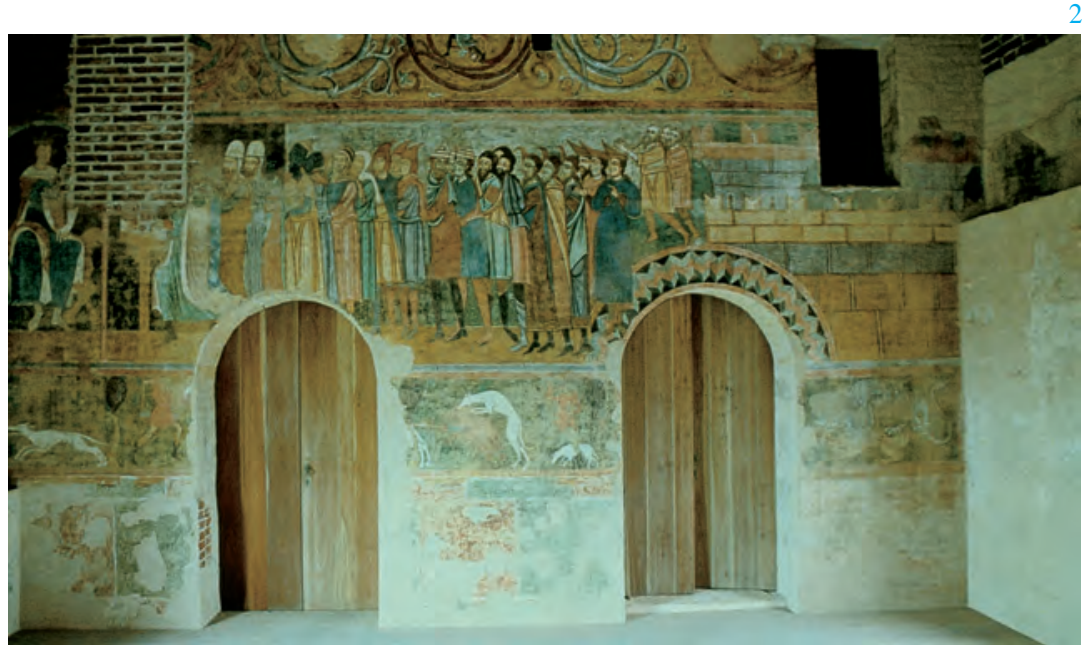

2. Sala de los frescos: la escena del cortejo después de la restauración

3. Vista de la torre y de parte del palacio abacial antes de los trabajos

4. Vista de la pared Norte de la torre donde se ven todavía las trazas de las faldas de la cubierta y los restos de sillares que delimitaban la amplitud del palacio

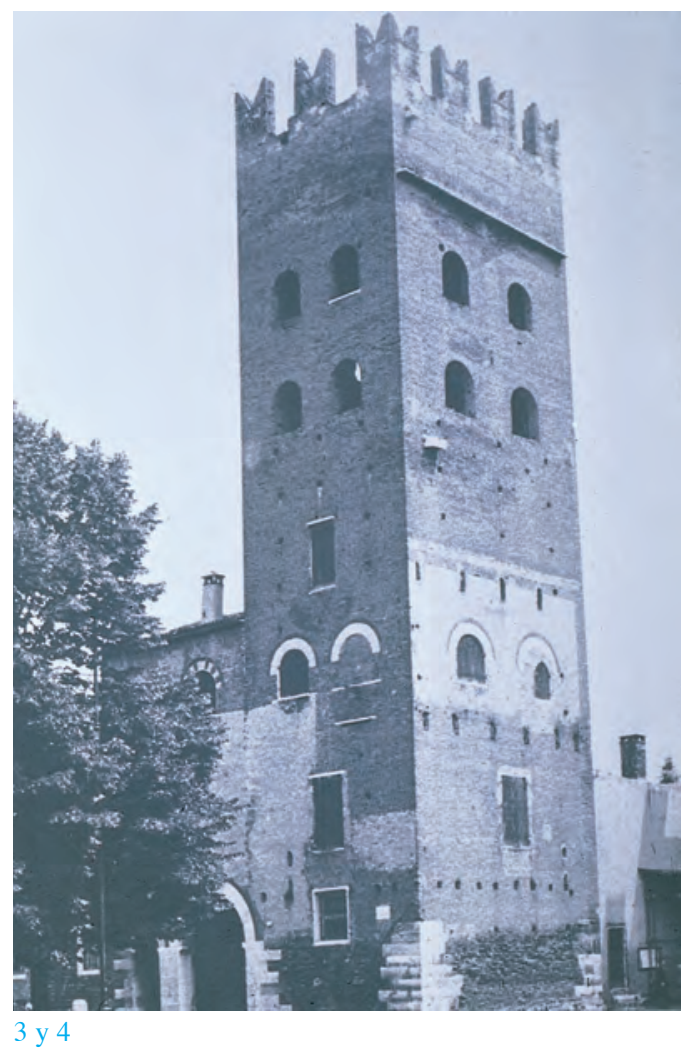

3 y 4

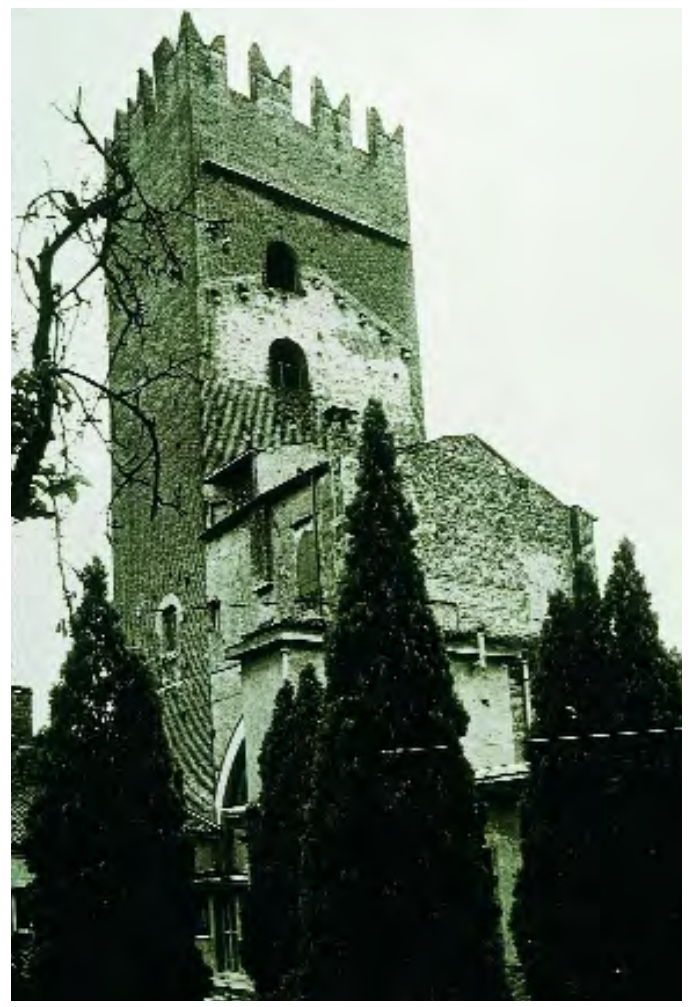



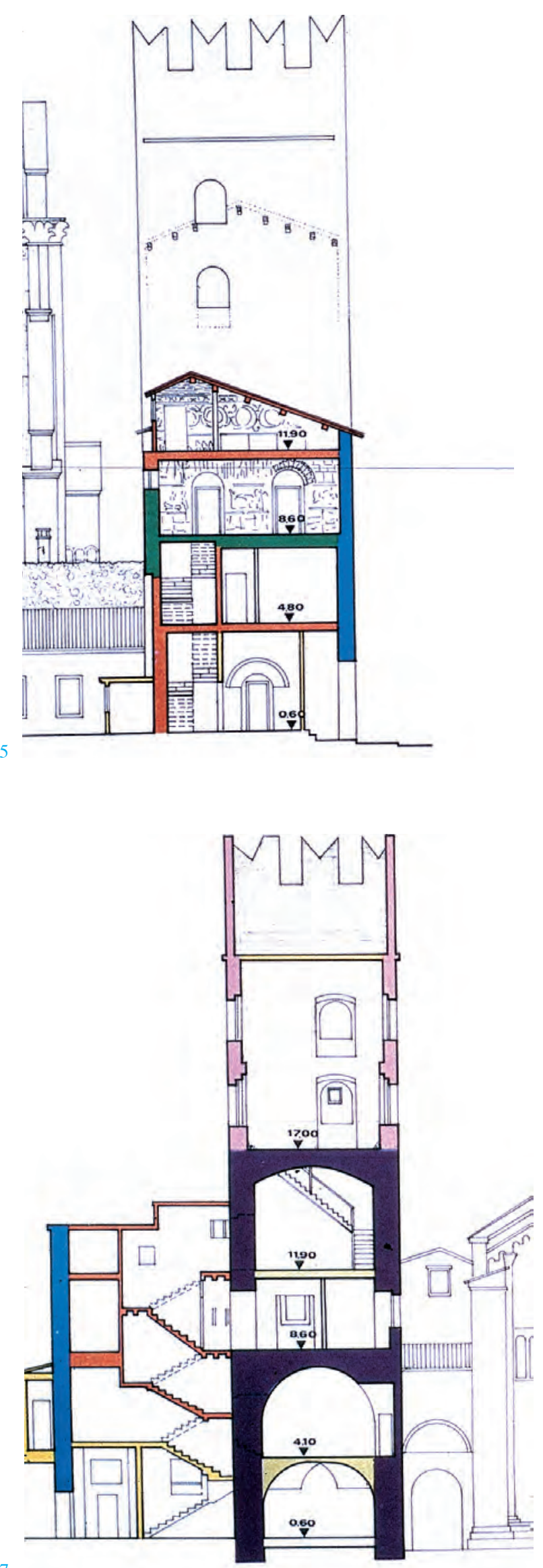
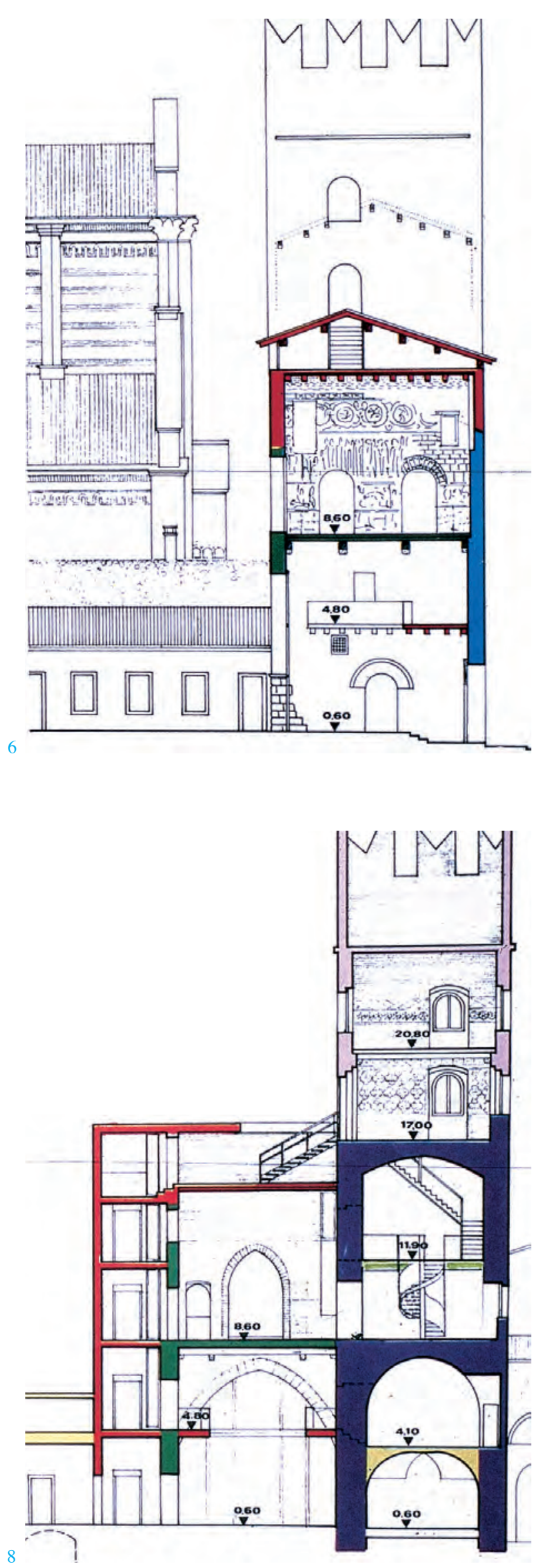
5 y 6. Lectura histórica de las estructuras: sección A-A, estado inicial y proyecto

7 y 8 . Lectura histórica de las estructuras: sección B-B, estado inicial y proyecto

9. Lectura histórica de las estructuras: levantamiento de la planta baja y proyecto
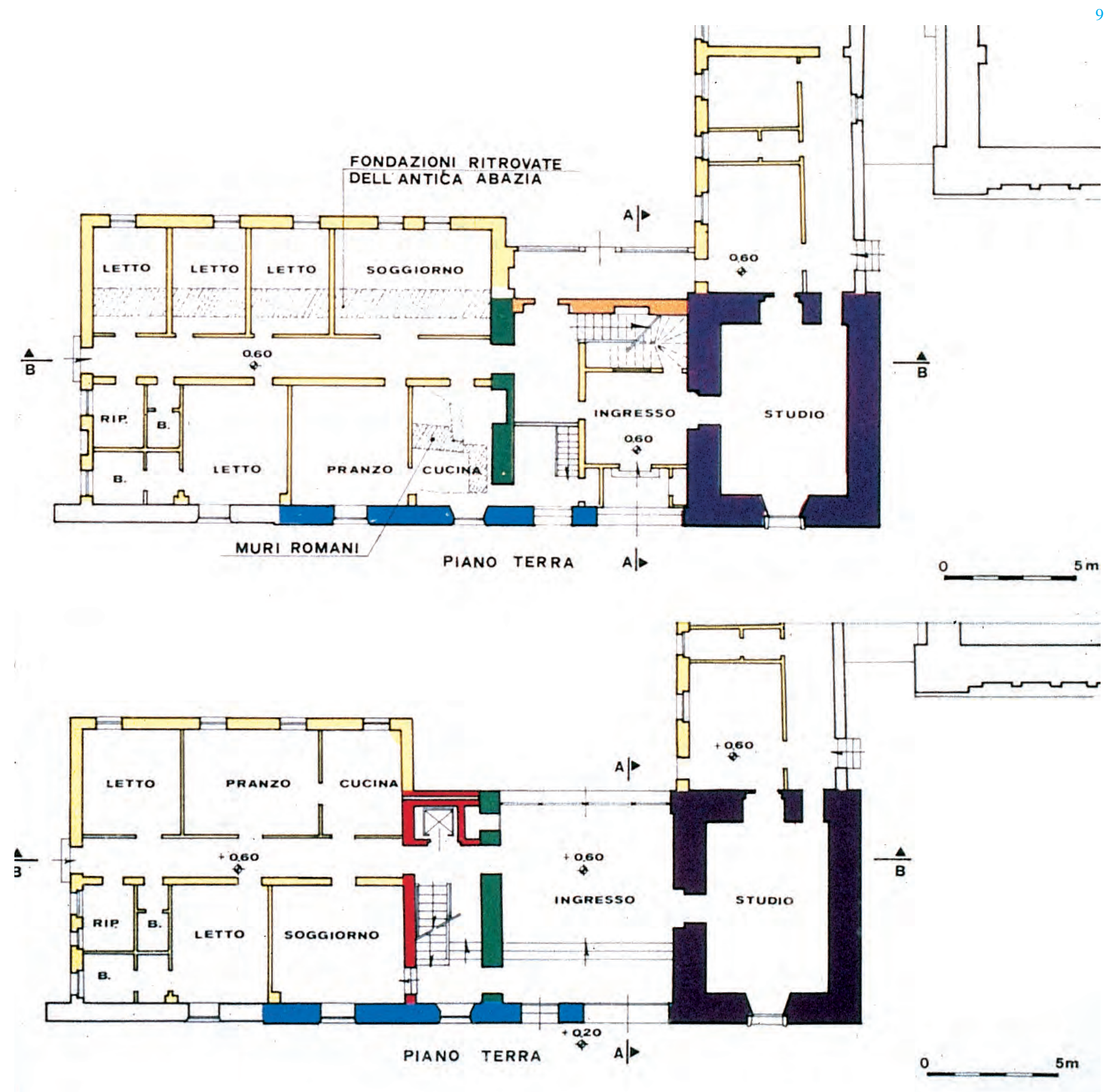


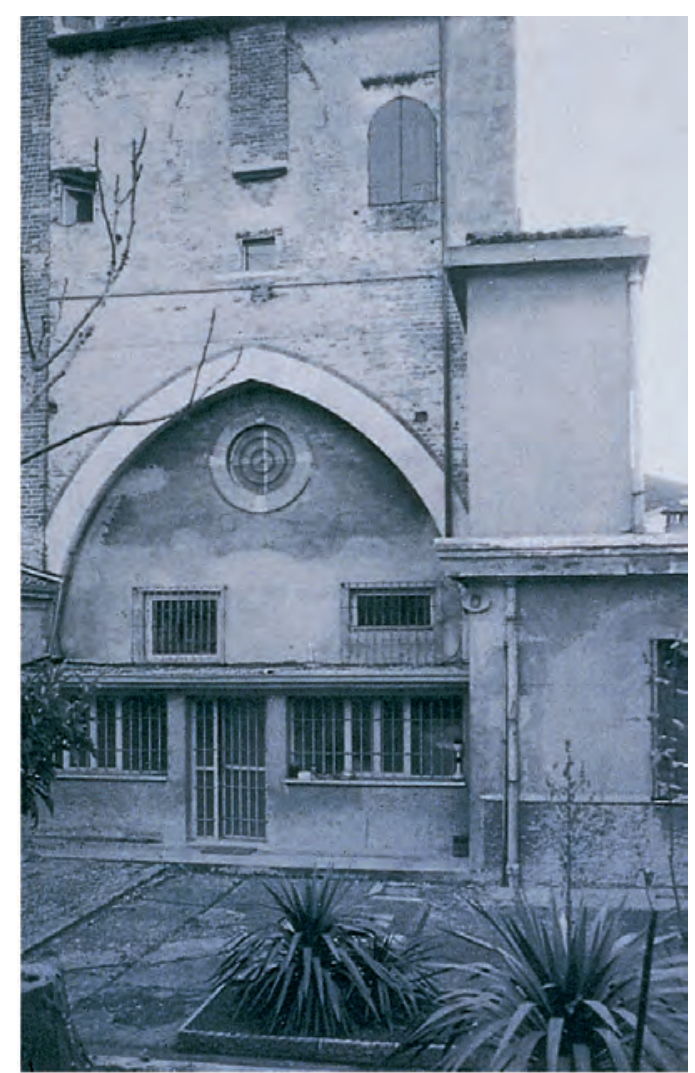

10

11

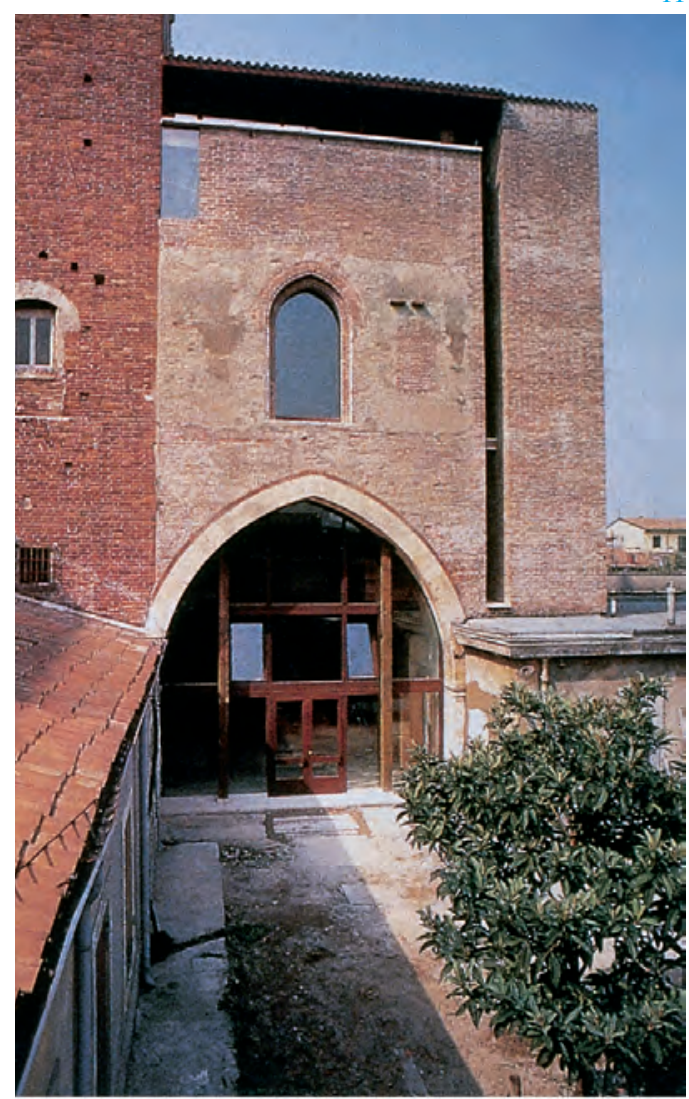

La torre y la residencia del abad fueron destruidas en parte a principios del siglo XIX y manipuladas con la inserción de varios forjados entre las plantas originarias y el añadido de una escalera y nuevos cuerpos adosados a la estructura antigua, presentaban un aspecto irreconocible al inicio de los trabajos.

La lectura del edificio abacial fue, en un principio, muy compleja. Éste se apoya sobre los cimientos de un edificio residencial de época romana, algunos de cuyos restos se han rescatado durante la excavación arqueológica. El fragmento más antiguo de la fábrica que se ha conservado hasta nuestros días constituye la pared occidental: en concreto, la parte sobre el arco de acceso, sin duda inmediatamente posterior a la primera fase de construcción de la torre, puesto que se adosa a ella. De hecho, los dos muros presentan una línea de separación externa bien definida. Como se ha observado anteriormente, esta pared poseía una longitud que casi doblaba la actual. En el interior se conserva el muro perpendicular a la misma, datable en torno al siglo XIV, que se adosa a ella y cubre un fresco que representa un escudo amarillo con águila imperial. Del mismo periodo es también la pared oriental, que se adosa a su vez al gran muro afrescado e impide parcialmente su lectura. Esta pared y la precedente constituyen las intervenciones que han transformado la logia en dos estancias cerradas.

Esta fachada luce un gran arco ojival en la planta baja y una ventana gótica en la primera que fueron cegados en el siglo XIX y se han recuperado durante la intervención (figs. 10 y 11). Otra operación del proyecto ha consistido en la eliminación de la única escalera existente (de hormigón en la planta baja y de madera en los niveles superiores) que se recibía contra el fresco y destruía su unidad (fig. 13). En consecuencia, el problema más complejo radicaba en el cambio de ubicación del bloque formado por la escalera y el ascensor, indispensables para acceder a la sala del fresco y a la torre. Para ello, se plantearon dos posibilidades:

La primera preveía la construcción de un volumen diferenciado del contexto en posición y en forma: se trataba de respetar el monumento sin perpetrar nuevas manipulaciones y erigir un bloque vertical moderno como contrapunto. La segunda opción, finalmente llevada a cabo, venía sugerida tanto por la necesidad de sobreelevar la cubrición de la estancia hasta la primera planta para permitir la lectura integral del fresco, como por el hallazgo en las excavaciones arqueológicas de los cimientos de la fachada interna de la abadía demolida en el siglo XIX.

Por tanto, el nuevo núcleo de escaleras se alojó en un volumen adosado al palacio abacial en línea con el muro de fachada, separando la nueva intervención de los restos antiguos mediante un ligero retranqueo en la fábrica de la fachada occidental y con una hendidura en la oriental. Para esta intervención se recurrió a un material semejante al antiguo: ladrillos hechos a mano, con la dimensión de los originales $(27 \times 13 \times 6 \mathrm{~cm})$ y cocidos en hornos alimentados con leña. Esta decisión pretendía armonizar la intervención con las preexistencias, considerando que la diferenciación necesaria entre antiguo y nuevo ya se obtenía en el aspecto formal (fig. 11). Otro problema residía en la restitución de la espacialidad originaria de la "sala del emperador" a través de la sobreelevación de la cubrición, en la medida necesaria para recrear el recorrido de unión con la puerta de la torre del siglo XIV (tapiada) sin alcanzar el nivel de la cubierta original y tratando 
de conferir un sentido de provisionalidad al nuevo techo, que se posa ligeramente sobre la fábrica gracias a una hendidura horizontal (figs. 5, 6, 7, 8 y 9). Con esta restauración se han recuperado todos los espacios originarios de la torre, a excepción del correspondiente a la planta primera, dividido en dos por un forjado decorado con una bóveda gallonada del siglo XVIII, que no se pudo demoler por su valor histórico y artístico. Por ello, para conectar este primer nivel del siglo XVIII de la torre con la nueva escalera se ha creado una galería de madera que gira en torno a los tres lados del cuerpo abacial y respeta la vista del arco ojival en toda su altura (fig. 12). Se ha intentado evitar el uso de elementos metálicos y recurrir a la utilización de madera y ladrillo bajo formas modernas, que se consideran materiales de mayor consonancia con la arquitectura monástica.

\section{METODOLOGÍA DE INVESTIGACIÓN Y RESTAURACIÓN}

Como se ha escrito, la torre y el palacio abacial son organismos complejos que forman parte de un conjunto edilicio más vasto. Para afrontar su restauración, se han efectuado diversos estudios gráficos, históricos, estructurales, etc. La metodología utilizada para iniciar la intervención ha consistido en la reunión de un equipo de investigadores y especialistas, cuya aportación ha pemitido afrontar el trabajo con frecuentes verificaciones y decisiones de proyecto.

Se han acometido los siguientes trabajos:

- Investigación histórica tanto de los textos como de los planos, dibujos y levantamientos, llevada a cabo por historiadores del arte, con cuyo estudio pueden ofrecer una visión del desarrollo en el tiempo de nuestro inmueble, indicando los cambios de uso, dimensiones de diversas estancias, añadidura de nuevos cuerpos.

- Levantamiento arquitectónico, altimétrico y arqueológico, efectuado por diversos especialistas destinado a confluir en un único proyecto.

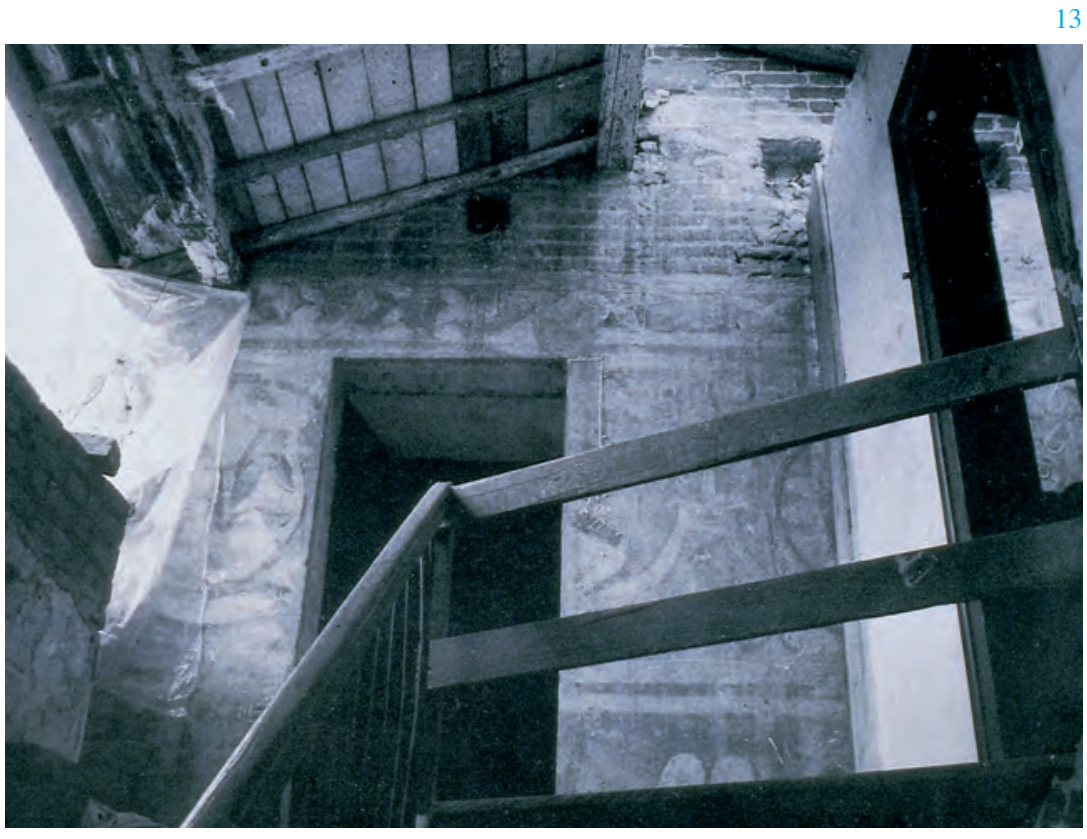

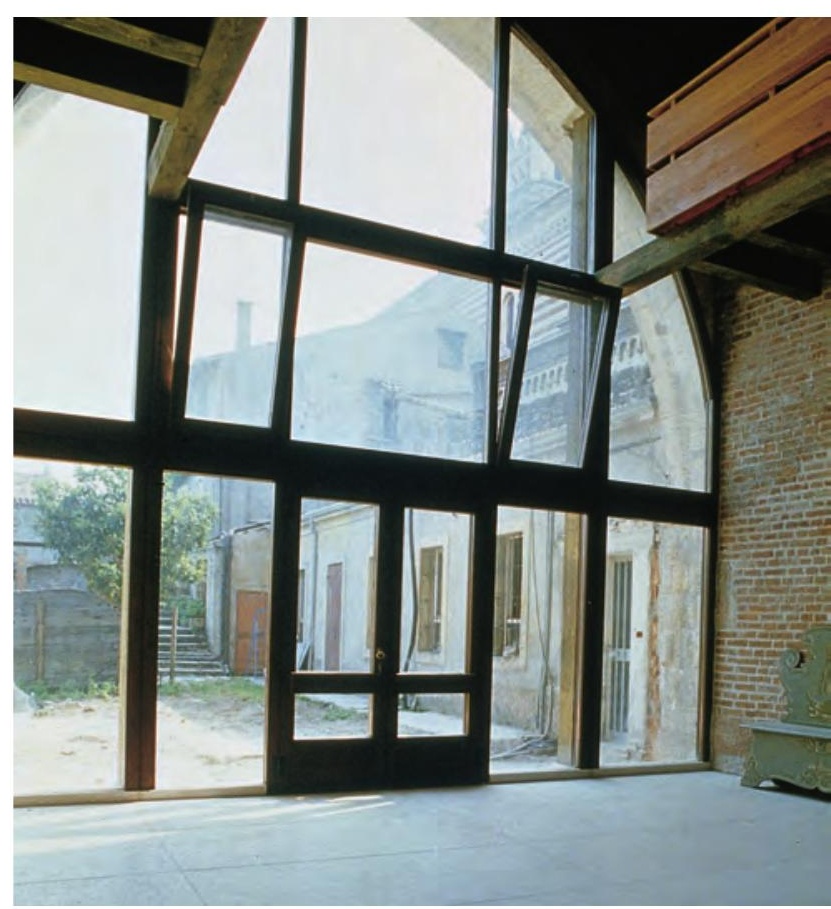

12

10 y 11 . Vista del tapiado del arco ojival y de los elementos de hormigón armado adosados al palacio abacial antes y después de los trabajos

12. Vista interna de la sala de acceso del palacio abacial 13. Vista de la puerta y de la escalera del siglo XIX insertadas en la pared septentrional afrescada de la torre 
Con esta opinión se alineó también el profesor Victor H. Elben de la Universidad de Berlín, quien, confrontando el estilo de la iconografía y la forma de este fresco con pinturas murales del Alto Ádige (ábside de la iglesia de San Giovanni di Müstair en Grigioni), confirmó la presencia de elementos comunes de ascendencia véneto-bizantina junto a un gusto ornamental con ascendencia nórdica. En la actualidad, este fresco es todavía objeto de estudio y el debate continúa abierto.

\section{RESTAURACIÓN DE LOS FRESCOS DE LA SALA DEL EMPERADOR}

Los problemas de la "lectura" de la compleja decoración mural en la "Sala del emperador" no eran sólo de carácter pictórico sino, sobre todo, de índole técnica y surgían a raíz del estado de degradación general de la obra y las graves mutilaciones sufridas, además de las restauraciones ocurridas en el transcurso de su historia (1926). Las fases de intervención han contemplado los siguientes pasos:

-demolición de los morteros de cemento y eliminación de parches en el enlucido, -prefijación de la película pictórica descohesionada con ayuda de Paraloid "B72", -limpieza de toda la superficie pictórica del cortejo con aplicación de emplastos de "AB57", y de las tres paredes decoradas con sillares falsos con emplastos de pulpa de papel y carbonato de amonio,

-fijación definitiva de la película de pintura mediante aplicaciones de agua de cal -relleno de las lagunas utilizando materiales inorgánicos: desde el cocciopesto a la cal, pasando por el polvo de mármol y arenas, excluyendo resinas,

-restauración pictórica y veladuras utilizando buenos pigmentos de fresco con metacrilato en emulsión acuosa fácilmente soluble.

\section{CONSOLIDACIÓN DEL FORJADO DE LA SALA DE LOS FRESCOS}

Se trata de un forjado con vigas principales de madera de abeto de 2,20 m de longitud, con una distancia entre ejes de 2,20 m, y viguetas también lígneas de menor escuadría que cubren una luz de $6,50 \mathrm{~m}$ y poseen un intereje de $80 \mathrm{~cm}$. En la sala de los frescos, se ha efectuado también una intervención de consolidación del forjado, que era estáticamente débil y no estaba en grado de soportar grandes cargas. La intervención de consolidación ha consistido en el vertido de una solera de hormigón, armada con una malla electrosoldada que se solidariza con las vigas y viguetas de madera a través de conectores de acero insertados en la estructura lígnea mediante resinas epoxídicas especiales para la madera. En el caso de las vigas, la solera se ha extendido hasta contactar con el borde superior de las mismas para que los conectores puedan funcionar a esfuerzo cortante y disponer de una mayor sección de hormigón colaborante (figs. 17 y 18).

\section{SUBSUELO: ESTRATIGRAFÍA Y CARACTERIISTICAS GEOTÉCNICAS}

La prueba litoestratigráfica del subsuelo se ha efectuado en la explanada ante la basílica de San Zeno, a una distancia de un metro de la torre. Las litologías presentes en el subsuelo hasta la profundidad sondeada están constituidas exclusivamente por gravas más o menos densas en matrices arenosas, arenoso-limosas y, a veces, arcillosas.
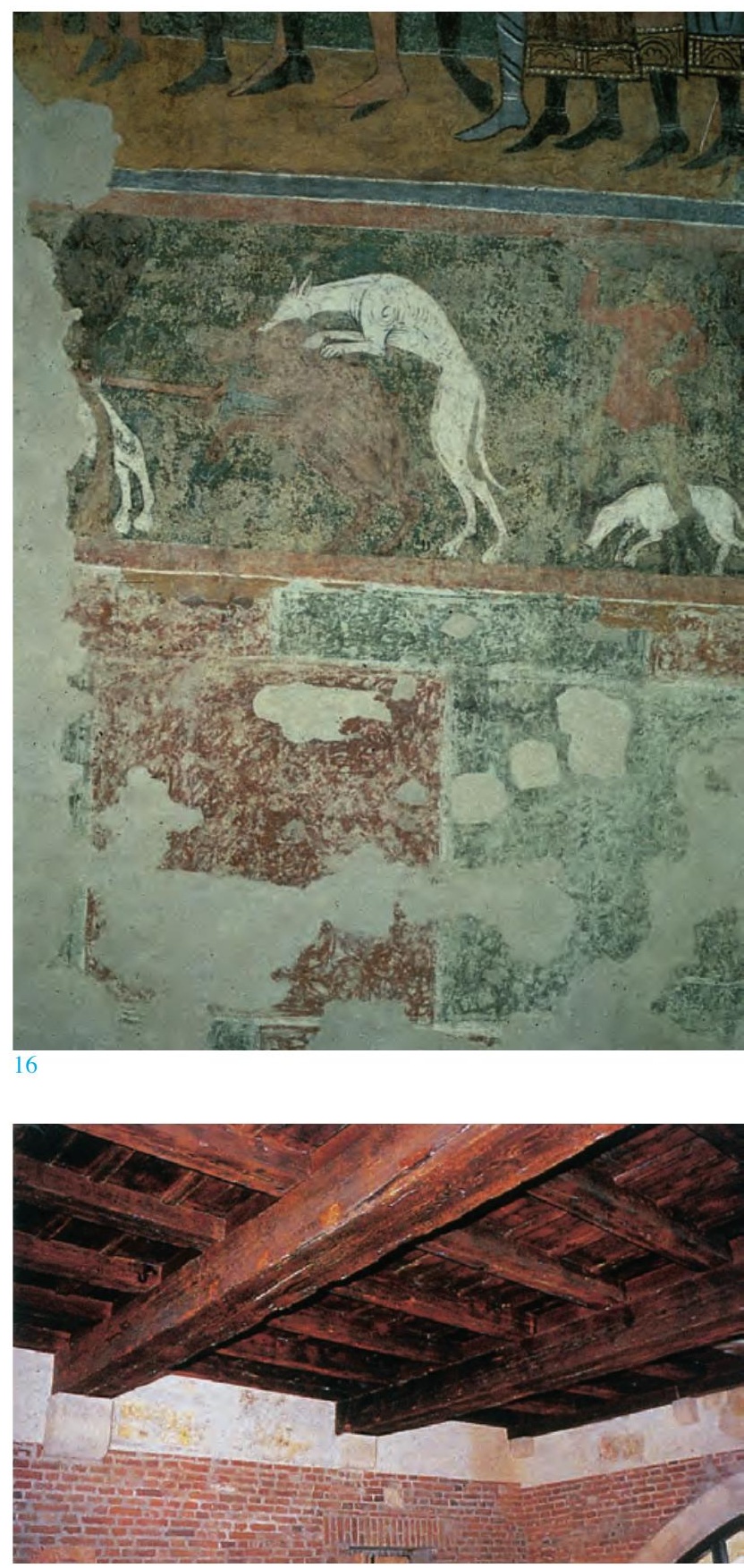

17 y 18

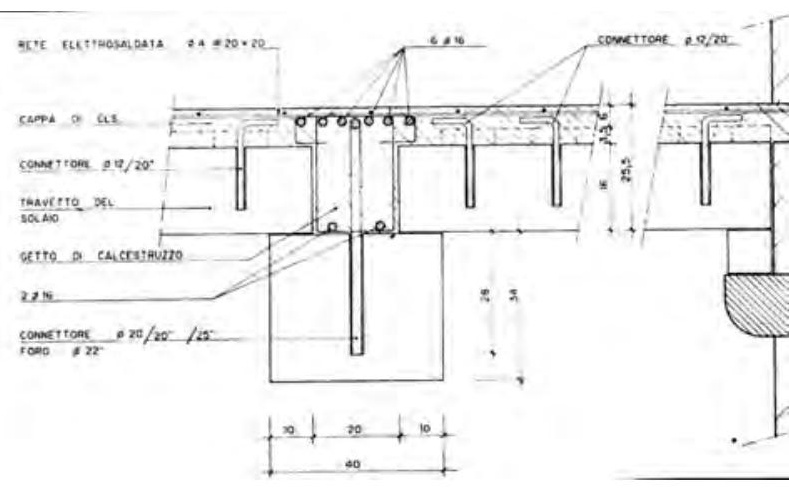


19. Modelo numérico con distribución de las tensiones inducidas por las cargas permanentes

20. Una fase de la prueba de las tensiones-deformaciones obtenida mediante gatos dobles sobre la fábrica del muro externo a la izquierda y sobre el estrato interno a la derecha 21 y 22. Diagramas de tensión-deformación obtenidos mediante una prueba con gatos planos dobles sobre la pared externa
19
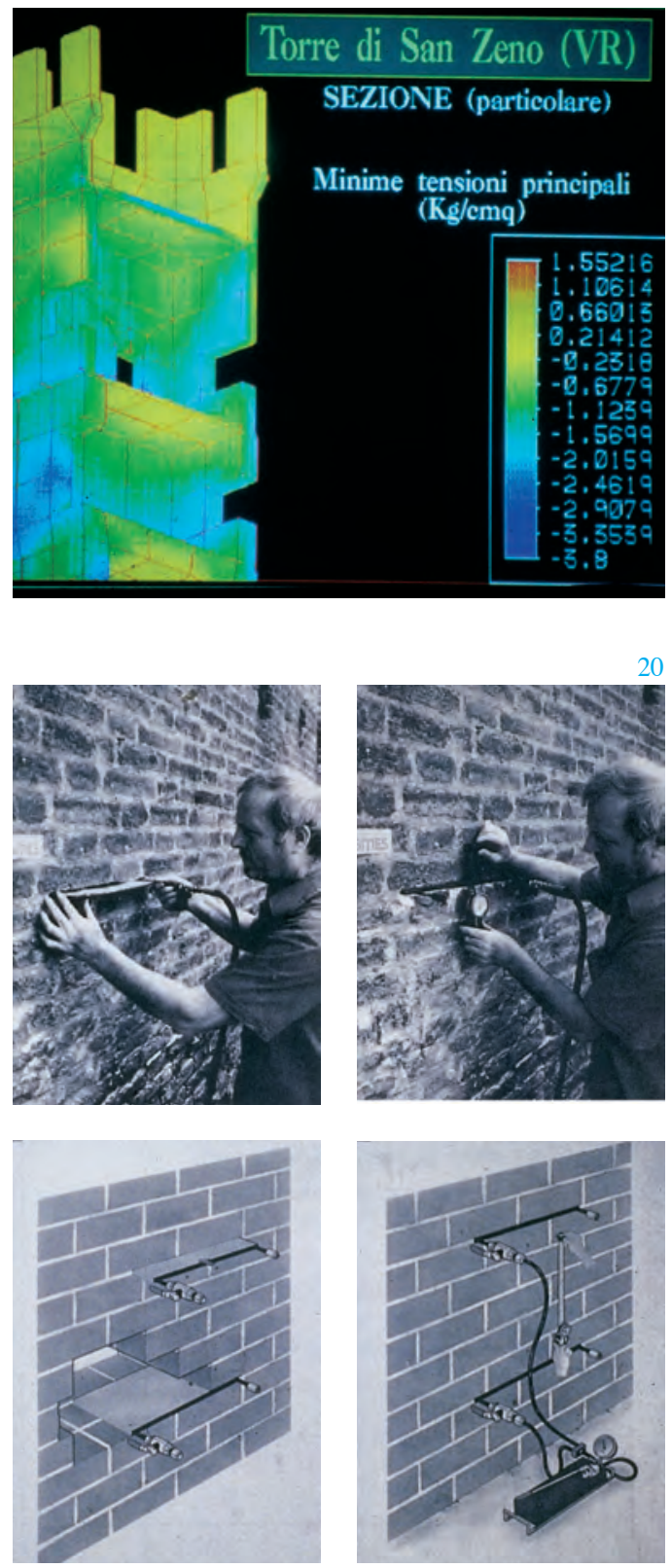

Únicamente el estrato superficial, con un espesor de 1,50 m aproximadamente, está constituido por limos y arcillas con presencia de materiales de aporte derivados de la demolición de edificios preexistentes. En el transcurso del sondeo se han efectuado, además, dos S.P.T. (Standard Penetration Test) a una profundidad de 3-3,45 $\mathrm{m}$ en el estrato de gravas con una ligera matriz arenosa y limosa, y a una profundidad de 6-6,45 $\mathrm{m}$ en el estrato de litotipos de grava con matriz arcillosa.

Los valores de estos test confrontados con curvas experimentales han permitido determinar las características geotécnicas principales de los litotipos estudiados y, de ellas, establecer su comportamiento mecánico inducido de la sobrecarga ejercida por el peso de la torre. Se ha podido comprobar que la capacidad portante de los terrenos de la cimentación de la torre abacial es relativamente elevada: aunque no se conozcan con precisión las características geométricas de la cimentación y asumiendo un coeficiente de seguridad de 3 , se ha estimado un valor de $4-5 \mathrm{~kg} / \mathrm{cm}^{2}$. Igualmente, dada la composición con predominio de gravas de los litotipos presentes en el subsuelo del área sondeada, se puede afirmar que los asentamientos del terreno de la cimentación de la torre, que siempre han sido de entidad limitada, tuvieron lugar en momentos breves durante o después de la aplicación de cargas derivadas del proceso constructivo ligado al nacimiento de la misma torre.

\section{ESTRUCTURA: COMPORTAMIENTO Y ESTADO DE CONSISTENCIA}

La investigación ha consistido, principalmente, en la determinación experimental y teórica del estado de esfuerzo presente en la proximidad de la base de la torre, para lo cual se ha utilizado una técnica especial de ensayo de carácter no destructivo.

Esta técnica se basa en la variación del estado tensional en un punto de la estructura provocada por corte plano de reducidas dimensiones efectuado en dirección perpendicular a la superficie de la fábrica a la altura de un tendel de mortero. En el interior de este pequeño corte se inserta un gato plano especial de dimensiones variables ( $400 \times 200 \mathrm{~mm}$ o 240 x $120 \mathrm{~mm}$ ) y espesor de 10 $\mathrm{mm}$, formado por finas láminas de acero soldadas, cuya presión interna se aumenta gradualmente hasta anular la deformación medida en la fase de ejecución del corte (figs. 19 y 20). En estas condiciones, la presión en el interior del gato equivale a la solicitación preexistente en la fábrica del muro en dirección perpendicular al plano del gato, afectada por un coeficiente empírico que tiene en cuenta la relación entre el área del instrumento y la del corte y la rigidez intrínseca de cada gato en particular que, después de la prueba, se recupera fácilmente para otros usos. Retirado el gato, se rellena el corte con mortero para devolver a la fábrica sus condiciones originarias. Con esta técnica se ha calculado la resistencia y la deformabilidad de los muros de la fábrica del edificio. Una pareja de gatos planos determinó la zona del muro a analizar y sobre ella se aplicó una carga de compresión, midiendo las deformaciones. Las curvas de tensión/deformación correspondientes (figs. 21 y 22) permitieron estimar el módulo de elasticidad del muro y ponderar su resistencia. 
Otra prueba importante ha sido la extracción mecánica de probetas cilíndricas horizontales, que han servido para determinar los materiales que constituyen los elementos estructurales de las construcciones revelando, en el caso de los muros a dos caras con relleno interior, los espesores correspondientes a la sección de los paramentos externos y el núcleo interno. Estas extracciones se efectúan mediante un taladro de avance manual con broca de corona de diamante y paredes finas. El fluido de refrigeración y las dimensiones de la corona son diversos en función de la tipología del muro. Las muestras así obtenidas permiten realizar pruebas de laboratorio de tipo mecánico y, sobre todo, físico-químico. Los agujeros de estas extracciones se inspeccionan con una microsonda televisiva de color (diámetro externo: 10,3 mm) con el objetivo de mejorar la información ya adquirida a través de la descripción del material extraído con la perforación; en concreto, en lo que atañe a la identificación y dimensionamiento de eventuales discontinuidades y cavidades presentes en la masa interna del muro. Además de todas estas pruebas, se han realizado también análisis numéricos empleando un modelo elástico lineal de elementos finitos sólidos de ocho nudos, donde a los materiales se les asignaron los valores de deformabilidad obtenidos en las pruebas con gatos planos dobles. Aunque la hipótesis de linearidad para un material como la mampostería sea, evidentemente, muy limitativa, no parece de momento muy real apoyarse en modelizaciones complejas no lineales, sobre todo debido a la dificultad práctica para caracterizar adecuadamente el material analizado. Por ello, no se ha menospreciado la utilidad de un modelo lineal: permite, de hecho, descubrir los efectos de la falta de homogeneidad (por ejemplo, entre los diversos paramentos que componen un muro antiguo) y de las discontinuidades geométricas, incluso en el caso de las derivadas de fenómenos macroscópicos de fisuración.

Este análisis permite asimismo aplicar un procedimiento interesante de estimación, basado en pruebas de carácter dinámico, que brindan la posibilidad de efectuar un control global del comportamiento de la estructura real. El procedimiento se basa en la confrontación entre los parámetros de la respuesta dinámica obtenidos a partir de los datos acelerométricos y los valores correspondientes ofrecidos por el modelo numérico.

Los resultados de las investigaciones emprendidas han constatado que los estratos más internos del muro presentan una elevada deformabilidad que, unida a la presencia de oquedades comporta una relativa sobresolicitación de los paramentos externos del muro. Se ha considerado oportuno, en consecuencia, sugerir la ejecución de inyecciones, si bien limitadas a la parte inferior de la torre, recomendando el uso de materiales que comporten riesgos menores desde el punto de vista físico-químico.

Se ha comprobado igualmente una carencia estructural local en la zona de la pared septentrional (donde se han registrado los picos más altos de tensión) debida al mal estado de la fábrica y a la separación entre el relleno interno y el paramento externo. En esta zona se ha intervenido, por tanto, con numerosas operaciones de sustitución individual de las piezas que integraban la fábrica de mampostería.

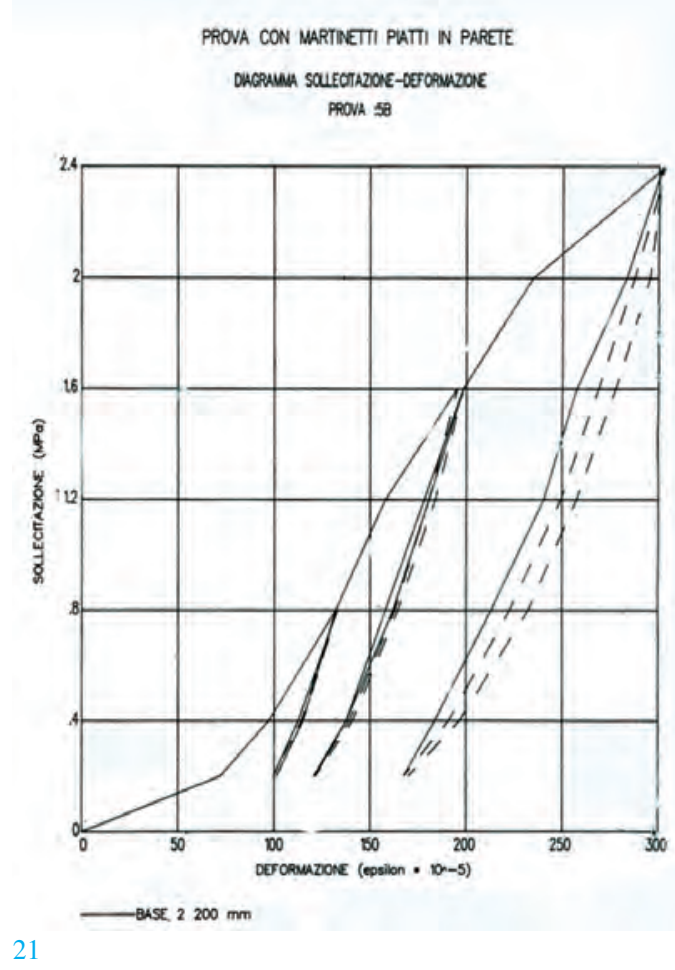

22

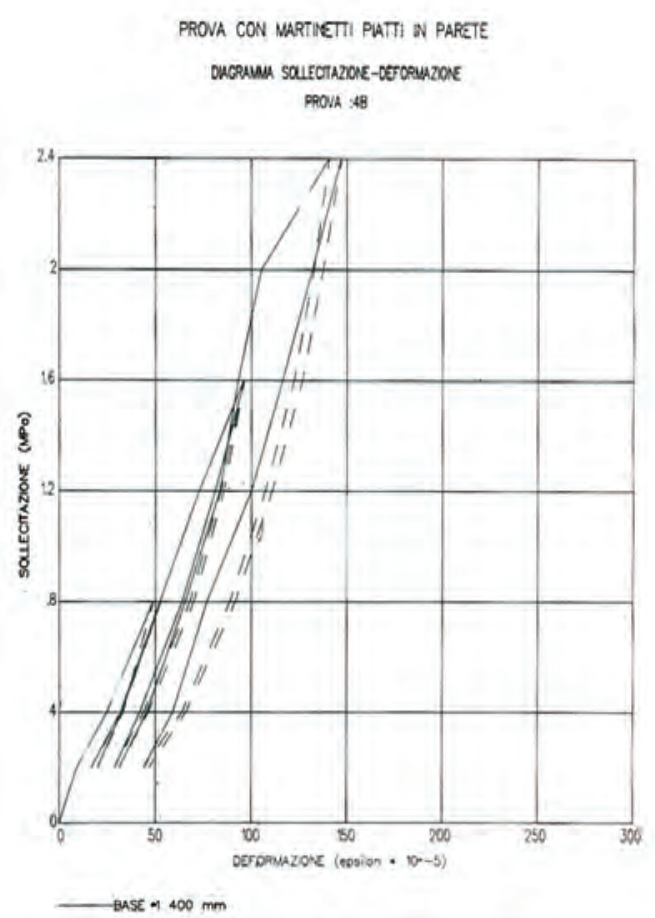


tal entre el cuarto y el quinto piso. La intervención ha repuesto este forjado a partir de los elementos que mostraban su posición: las ménsulas de mármol que sostenían las vigas, los mechinales que indicaban la posición de las viguetas y el retranqueo de la pared de ladrillo, bien visible en los cuatro lados (fig. 24).

En las cuatro paredes se despliegan motivos polícromos de carácter geométrico con formas de palmetas, tetralóbulos y dameros que conciertan partituras ornamentales diversas. De la incisión de un grafito (un emblema heráldico de Mastino II della Scala) ubicado sobre el estrato afrescado, se puede afirmar que estas decoraciones datan en torno al primer veintenio del siglo XIV.

En busca de una mayor profundización, se han efectuado los levantamientos gráficos para el estudio geométrico de la estructura decorativa; éste es el caso de los diseños de palmetas o tetralóbulos, nacidos claramente de una serie de círculos superpuestos (fig.25).

Relacionando estos análisis con los estudios efectuados previamente sobre decoraciones textiles medievales ("Le stoffe di Cangrande"), se puede afirmar que este "ropaje" de la pared, a base de formas tetralobuladas, nace de la fusión entre el espíritu clásico y el bizantino. Estos frescos, confrontados también con otras ornamentaciones conservadas en los interiores veroneses afrescados, señalan un léxico común en origen.

En San Zeno, en concreto, estos ritmos geométricos permiten observar la correspondencia existente entre el espacio arquitectónico y el entorno ornamental según los cánones característicos de la cultura próxima al círculo de Giotto. De hecho, este pintor fue huésped de los Scaligeri en Verona y realizó intervenciones en su palacio, influyendo como era natural en el ambiente cultural ciudadano.

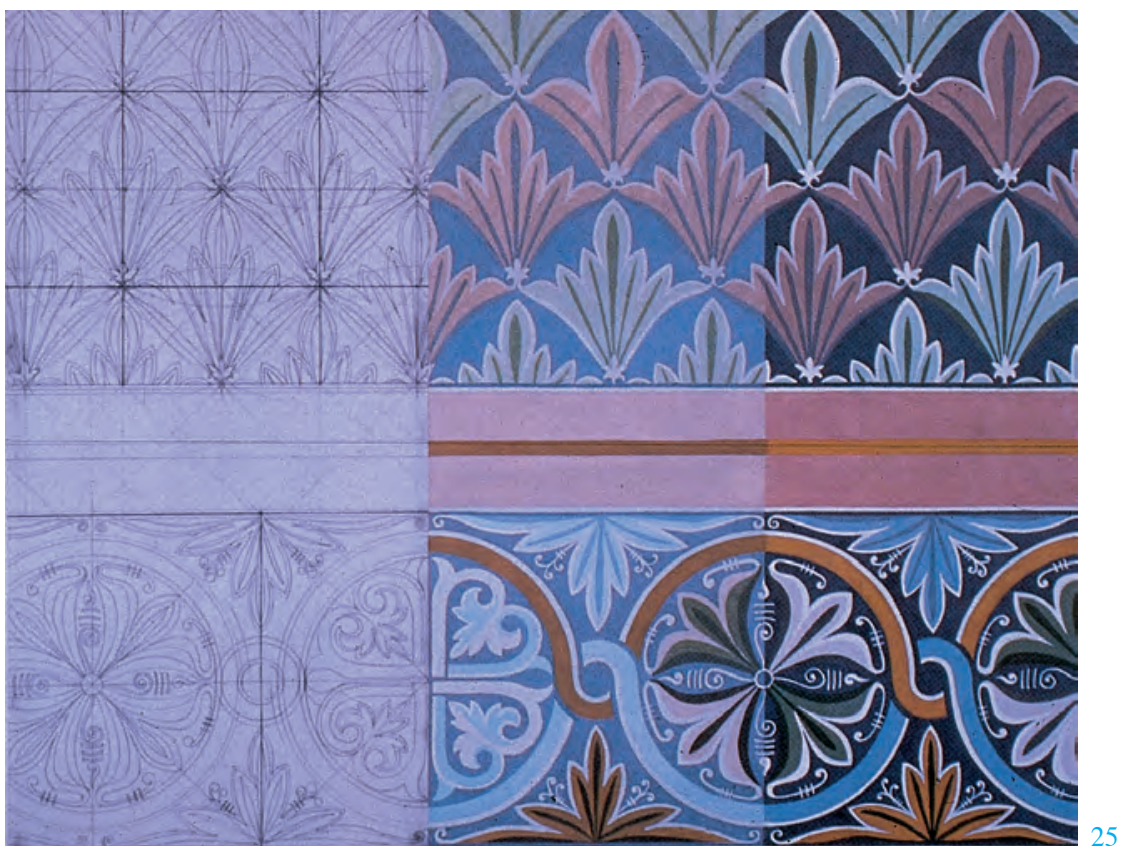

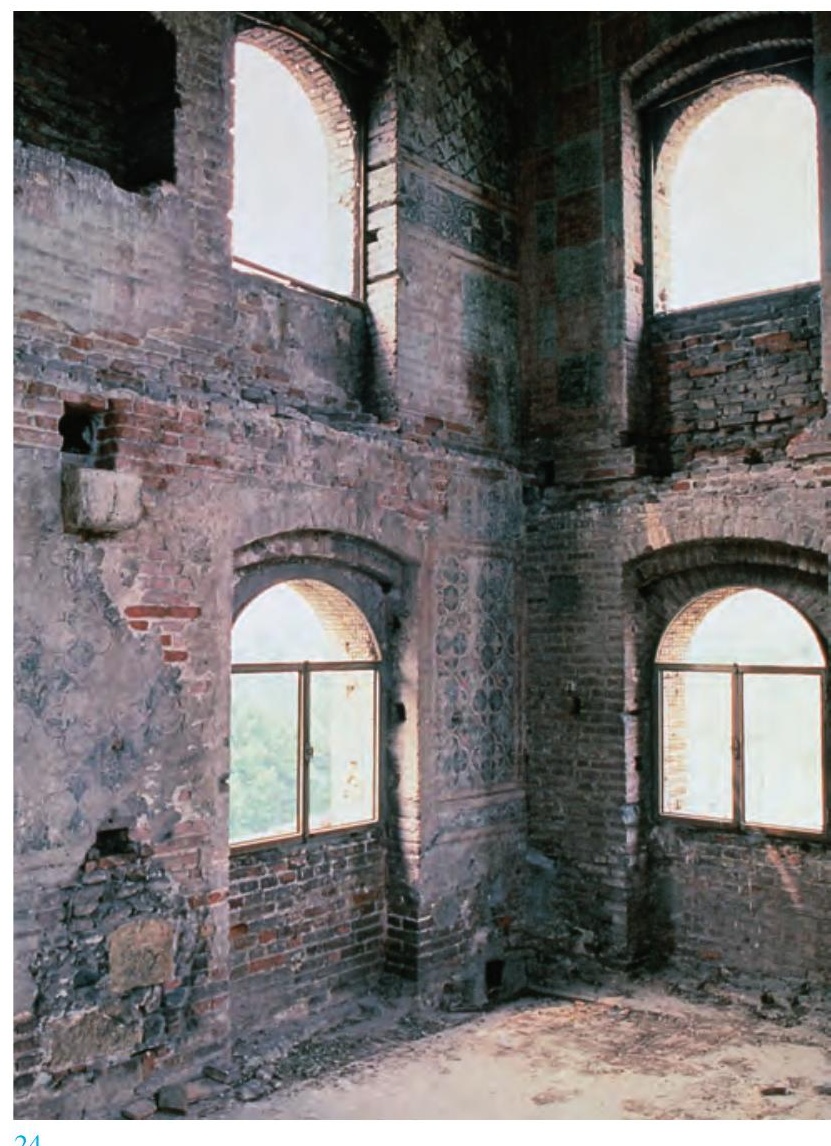

24 